\title{
3D SCANNING - ACCURACY OF A VOLUME MODEL TRANSFORMED FROM SCANNED DATA
}

\author{
Dana Kubatova \& Aneta Kaufnerova
}
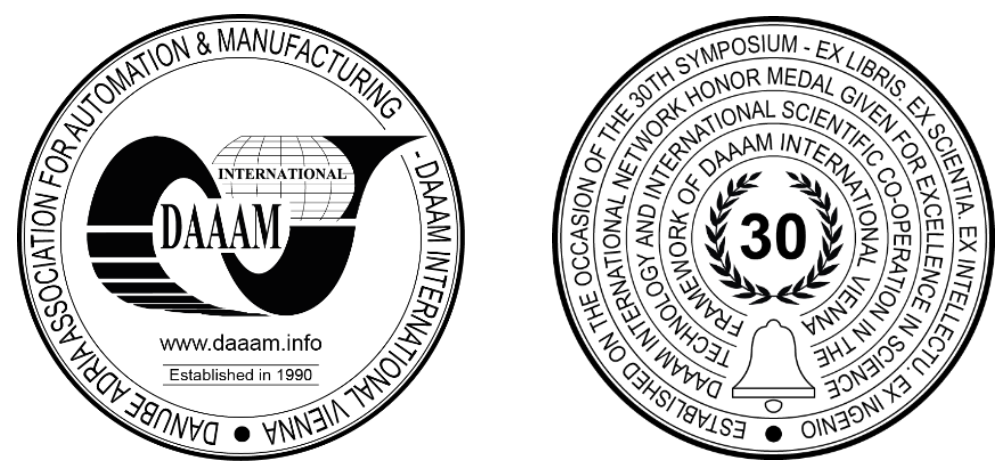

This Publication has to be referred as: Kubatova, D[ana] \& Kaufnerova, A[neta] (2021). 3D Scanning - Accuracy of a Volume Model Transformed from Scanned Data, Proceedings of the 32nd DAAAM International Symposium, pp.01400144, B. Katalinic (Ed.), Published by DAAAM International, ISBN 978-3-902734-33-4, ISSN 1726-9679, Vienna, Austria

DOI: $10.2507 / 32$ nd.daaam.proceedings.022

\begin{abstract}
Quality control is one of the most important areas in the production process. Quick inspection requires the most efficient techniques for comparing and inspecting manufactured parts with CAD design. One of the methods for evaluating product quality is to compare the CAD model with the scanned data. However, it may also happen that the customer wants to compare two production technologies for the same component. This issue is the topic of this article. The resulting deviations are circa $1 \mu \mathrm{m}$. This finding is satisfactory, and it is possible to use the converted model from the scanned data as reference data and thus compare products produced by another technology or apply it to another problem. Today, 3D scanning is a commonly used method for inspecting products. This work is based on a real situation that can help other solvers. The result of this work is to determine the deviation of the conversion of scanned data to a volume model in Geomagic control X.
\end{abstract}

Keywords: Scanning; Geomegic control X; CMM; Volume model.

\section{Introduction}

Product accuracy and quality control are an integral part of the production process. Until recently, the inspection of components, i.e. the measurement of dimensional and shape accuracies, was previously performed only by conventional methods, such as the contact method on a coordinate measuring machine (CMM). The data obtained by contact measurement are very accurate, but in some cases this method of measurement is insufficient, e.g. measurement of complex surfaces, soft or flexible products. The detailed surface of the part is measured by a sufficient density of points, which are obtained with difficulty using the contact method and it is very time consuming. For this reason, the measurement of complex surfaces using the contactless method, with 3D scanners, came to the fore. This modern measurement method is very fast, and, thanks to the overall description of the measured component, they enable us to perform complex and illustrative analyses easily. The transfer of real shapes to virtual 3D models is increasingly appearing in classical engineering due to the greater availability of scanning technologies. [1,7] One of the biggest advantages of $3 \mathrm{D}$ scanning is the fast acquisition of an accurate three-dimensional model. The model created by scanning can then be used for production using, for example, stereolithography, rapid prototyping or conventional CNC machining. [2,6] 
One of the methods for evaluating product quality is to compare the CAD model with the scanned data. However, it may also happen that the customer wants to compare two production technologies of the same component. This issue is the topic of this article.

\section{Methodology}

The required result from the measurement is to compare two products made by different technologies. One is made by unconventional technology and the other is made by conventional technology. [7], [8] This requirement can be met by comparing the scanned data with the "3D colour map" function, but this is only possible when the model is selected as the reference data. There is a problem here as to the exact conversion from the scanned data to the volume model in Geomagic control X 2020. The measurement was performed on a coordinate measuring machine at the Regional Institute of Technology at the University of West Bohemia in Pilsen. The measured object is a sample (Fig.1) that was printed from PLA material on the Prusa MK3S 3D printer (Fig. 2).

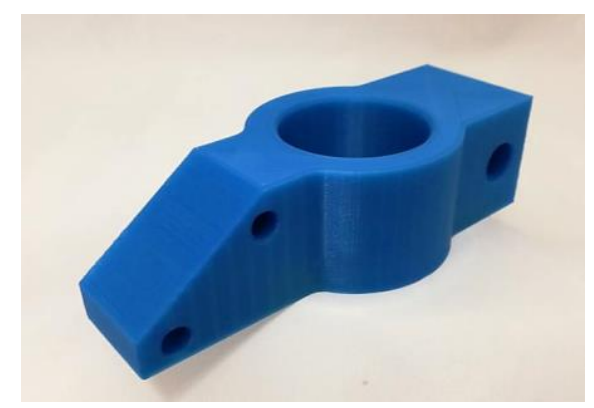

Fig. 1. The sample

\subsection{The equipment}

The sample was printed on a Prusa MK3S (Fig. 2) developed by Prusa Research. The filament used was Prusament PLA Azure Blue.

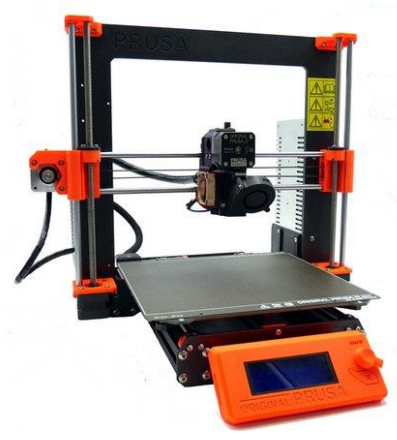

Fig. 2. PRUSA MK3S

The Laboratory of Workshop Metrology, which belongs to the Regional Institute of Technology, has a CMM from Zeiss, Prismo 7 Navigator (Fig.3). This machine is a bridge type CMM. This type is ideal for all measuring tasks. It accurately measures the geometry of a work piece along X, Y and Z axes using a contact probing system and optical probing system. The Prismo 7 Navigator measures lengths with a maximum permissible error of $0.9+\mathrm{L} / 350 \mu \mathrm{m}$.

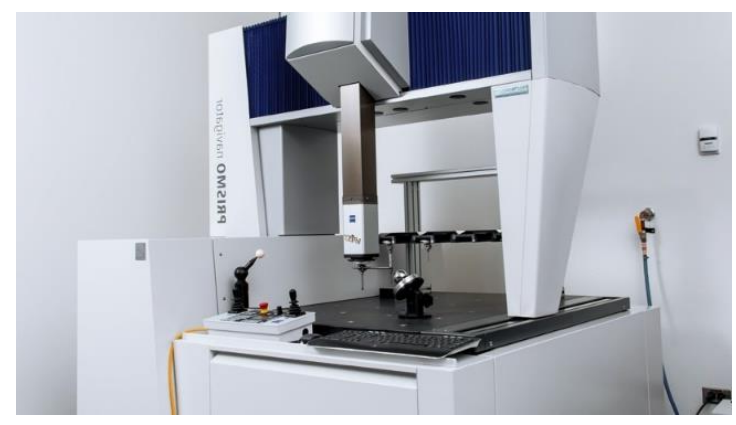

Fig. 3. Prismo 7 Navigator 
The machine has two heads, the RDS rotary head and the VAST XXT fixed head. It is possible to clamp both the head for contact measurement and the sensing system for LineScan (Fig.4) in the rotating head. LineScan is an optical laser line scanner designed for high-speed data digitization. It records 250000 points per second and is compatible with Calypso software. It is also possible to monitor the recorded data in the WBscan software over time.

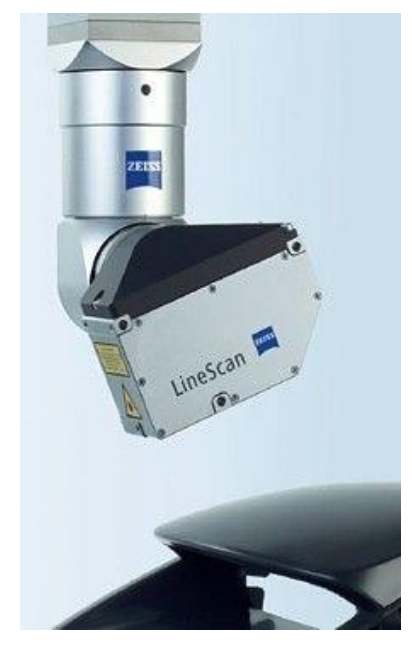

Fig. 4. LineScan

Software used:

- Calypso version 2020

- Geomagic Design X

- Geomagic Control X

- WBscan

\subsection{Procedure}

\subsubsection{Data scaning}

The scanner was calibrated before the measurement. The sample was then set on a cube for better scanner accessibility. The scan was divided into 3 measurements. [9] QSP (Qualified Surface Points) and RSL (Raw Scan Lines/Points) data were exported for further editing of the scanned data.

\subsubsection{Work with data}

Subsequently, the data were edited in Geomagic Design X software. Editing data in Geomagic Design X:

- Filter out noise from scanned points

- Smooth points to the middle level

- Convert points to a fine mesh

- Fill the holes

- Create the 3D model

- Export the mesh in stl format and the 3D model in step format
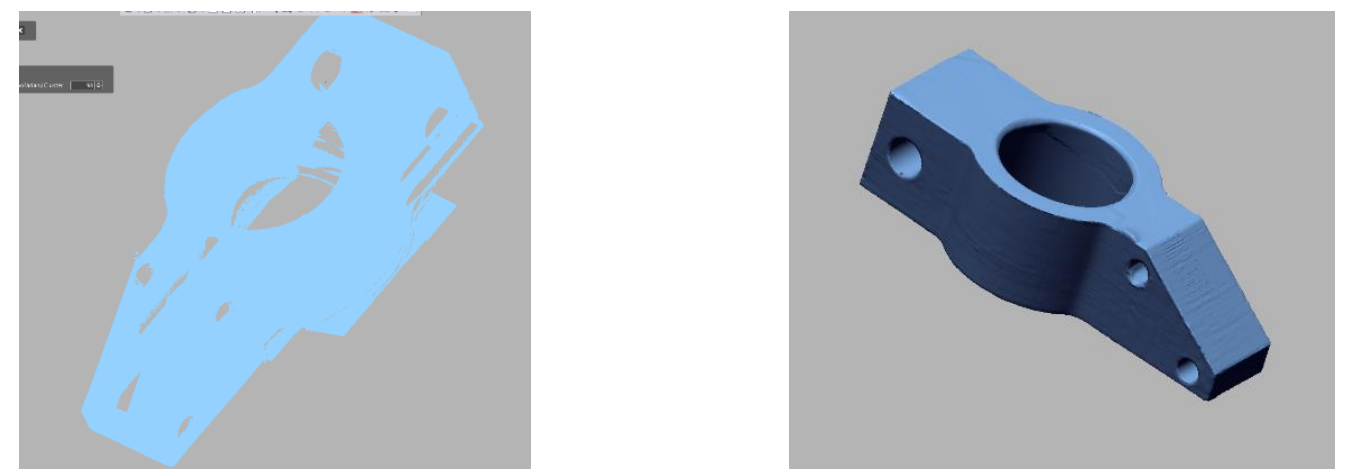

Fig. 5. A point cloud on the left and a polygon mesh on the right 


\subsubsection{Data analysis}

Individual meshes and 3D models were compared by 3D comparison in Geomagic Control X. The procedure in Geomagic Control $\mathrm{X}$ is:

- Import reference data (model volume)

- Import polygon mesh

- Align imported data

- Adjust the colour scale range and accuracy of the 3D scanner

- 3D analysis

\section{Evaluation in Geomagic Control $\mathbf{X}$}

First, the 3D model and mesh, which were created from RSL point clouds, were compared. As shown in the figure below, the selected colour scale range was \pm 0.5 and the specific tolerance of the $3 \mathrm{D}$ scanner was \pm 0.025 . According to the colour scale, the conversion of the RSL mesh to the model is high quality (in green). $95.075 \%$ of values are in a tolerance of $\pm 0.025 \mathrm{~mm}$. The lowest point is $-0.2006 \mathrm{~mm}$ and the highest point is $+0.2031 \mathrm{~mm}$. These points are out of tolerance. This can cause defects in the measured object, insufficient mesh conversion, or scanning of RSL points that represent all scanned points.

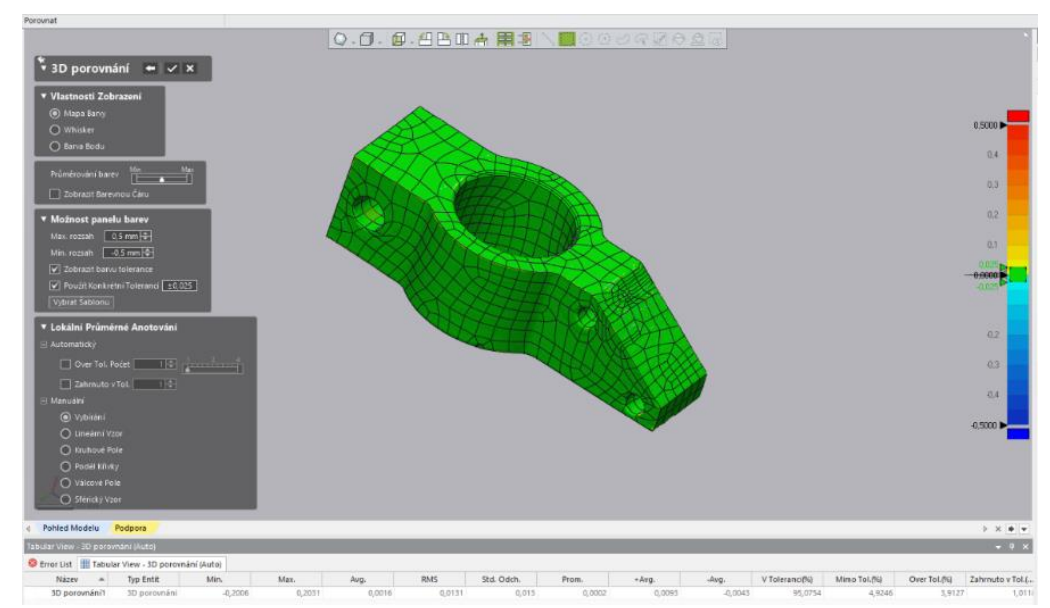

Fig. 6. The comparison - RSL volume model with RSL polygon mesh

According to the calculated results, the average value is $0.0016 \mathrm{~mm}$. This value expresses how good the conversion of the RSL mesh to the model is. Second, the mesh from QSP data and the model transferred from this mesh were compared. As shown in the figure below, the colour scale range was \pm 0.5 and the specific tolerance of the 3D scanner was $\pm 0.025 \mathrm{~mm} .96 .0748 \%$ of values are in the tolerance of $\pm 0.025 \mathrm{~mm}$. The lowest point is located at $-0.0828 \mathrm{~mm}$ and the highest point is at $+0.083 \mathrm{~mm}$. According to the calculated results, the average value is $0.0014 \mathrm{~mm}$. The average value is smaller than for RSL points because QSP points are calculated by a mathematical operation and RSL points are real scanned points.

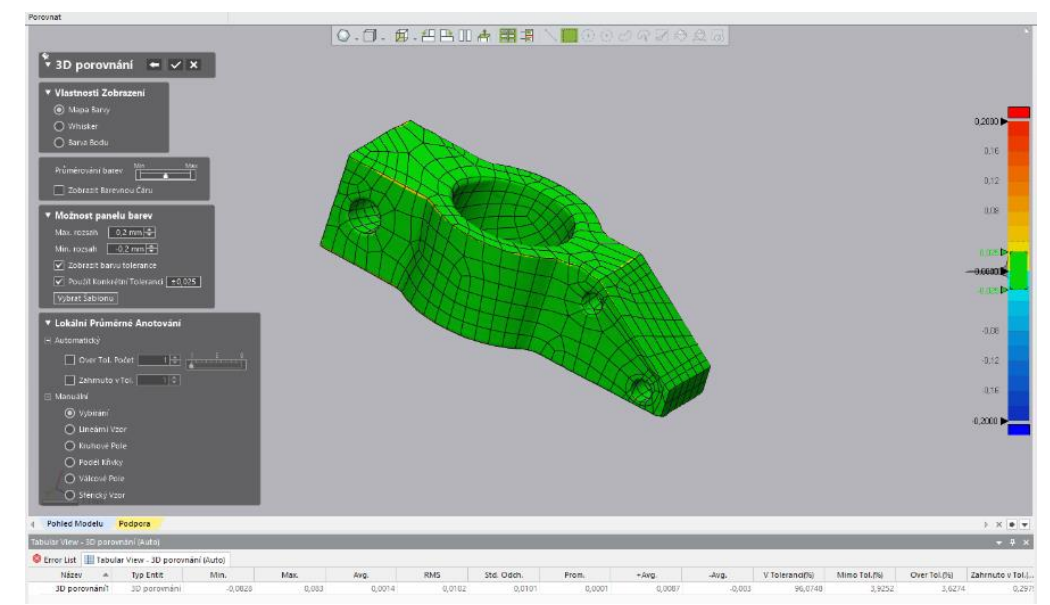

Fig. 7. The comparison - QSP volume model with QSP polygon mesh 
The resulting values of the converted models differ according to the selected scanned data (QSP, RSL). The resulting deviations are circa $1 \mu \mathrm{m}$. This finding is satisfactory, and it is possible to use the converted model from the scanned data as reference data and thus compare products produced by different technologies or apply it to another problem. Slightly better results are obtained from QSP, namely $0.0002 \mathrm{~mm}$.

\section{Conclusion}

Product accuracy and quality control is an integral part of the production process. Until recently, the inspection of components, i.e. the measurement of dimensional and shape accuracies, was previously performed by conventional methods, such as contact method on a CMM. The data obtained by contact measurement are very accurate, but in some cases this method is insufficient, e.g. measurement of complex surfaces, soft or flexible products. These parts are more often measured by noncontact methods. One of these methods is 3D scanning. Today, 3D scanning is commonly used for inspecting products. This work is based on a real situation that can help other designers. The measured object is a printed sample on a 3D printer that was scanned using a CMM. The scanned data was further edited and converted to mesh and 3D models. These were further compared and analysed.

The aim of this work is to determine the deviation of the conversion of scanned data to a 3D model in Geomagic control X. The resulting deviations are circa $1 \mu \mathrm{m}$. From the resulting values, it can be concluded that the conversion of the scanned data does not affect the resulting measurement. Thanks to these results, this step can be applied to compare the same parts produced by different technologies (3D metal printing, milling, etc.). The article describes only a part of the research that is carried out in this area within the University of West Bohemia in Pilsen. This research will help members of the metrology laboratory and perhaps not only check parts faster and easier that cannot be measured by contact methods.

\section{Acknowledgments}

This paper was created under the project GA UWB in Pilsen: SGS-2019-008 "Research and development for innovation in the field of manufacturing processes - Technology of metal cutting III".

\section{References}

[1] Sze S. M., and Leciejewicz J.; (1969) Physics of Semiconductor Devices (New York: Wiley-Interscience)

[2] Caplar R., and Kulisic P.; (1973) Density matrix theory of coherent ultrafast dynamics Proc. Int. Conf. on Nuclear Physics (Munich) vol 1 (Amsterdam: North-Holland/American Elsevier) p 517

[3] Lomakin V. O., Kuleshovav M. S., and Bozh'eva S. M. (2016) Numerical Modeling of Liquid Flow in a Pump Station Power Technology and Engineering 49 (5) pp 324-327

[4] Lomakin V. O., Kuleshova M. S., and Kraeva E. A.; (2015) Fluid Flow in the Throttle Channel in the Presence of Cavitation Procedia Engineering 106 p 27

[5] Christie B.; (2014) Quality Online Learning and Teaching (QOLT) Evaluation Instrument Sections and Objectives (California State University) (http://qolt.sfsu.edu/sites/default/files/QOLT2pgnumberslogoCore24CClicense111715.pdf) accessed 20 November 2016

[6] Stojkic, Z[eljko]; Culjak, E[va] \& Saravanja, L[uka] (2020). 3D Measurement - Comparison of CMM and 3D Scanner, Proceedings of the 31st DAAAM International Symposium, pp.0780-0787, B. Katalinic (Ed.), Published by DAAAM International, ISBN 978-3-902734-29-7, ISSN 1726-9679, Vienna, Austria DOI: 10.2507/31st.daaam.proceedings. 108

[7] Sykora, J[indrich] (2020). Additive Manufacturing of Unmanned Aerial Vehicle, Proceedings of the 31st DAAAM International Symposium, pp.0836-0841, B. Katalinic (Ed.), Published by DAAAM International, ISBN 978-3902734-29-7, ISSN 1726-9679, Vienna, Austria DOI: 10.2507/31st.daaam.proceedings. 117

[8] Habrman, M[artin] (2019). Influence of the Infill on the Tensile Strength and the Economic Factors of 3D Printing, Proceedings of the 30th DAAAM International Symposium, pp.1056-1060, B. Katalinic (Ed.), Published by DAAAM International, ISBN 978-3-902734-22-8, ISSN 1726-9679, Vienna, Austria DOI: 10.2507/30th.daaam.proceedings. 147

[9] Tatarevic, M[ichal]; Gapinski, B[artosz] \& Swojak, N[atalia] (2019). The Use of Optical Scanner for Analysis of Surface Defects, Proceedings of the 30th DAAAM International Symposium, pp.0076- 0085, B. Katalinic (Ed.), Published by DAAAM International, ISBN 978-3-902734-22-8, ISSN 1726-9679, Vienna, Austria DOI: 10.2507/30th.daaam.proceedings.010 